\title{
Analysis of the Correlation Among Age, Disc Morphology, Positive Discography and Prognosis in Patients With Chronic Low Back Pain
}

\author{
Seung-Min Kim, MD, Sang-Heon Lee, MD, PhD, Bo-Ram Lee, MD, Jeong-Won Hwang, MD
}

Department of Physical Medicine \& Rehabilitation, Korea University School of Medicine, Seoul, Korea

\begin{abstract}
Objective To investigate the correlation among age, disc morphology, positive discography, and prognosis in patients with chronic low back pain.

Methods A total of 183 intervertebral discs in 72 patients with chronic low back pain were studied. Discography was performed using a pressure-controlled manometric technique. The pain reaction during discography at each level was recorded as follows: no pain, dissimilar pain, similar pain, or concordant pain. Discs with similar or concordant pain were classified as positive. All the examined discs were assessed morphologically using axial computed tomography imaging. The grade of general degeneration and annular disruption of the discs were assessed according to the Dallas discogram description (DDD). Intradiscal injection of steroid was tried for patients with symptomatic disc identified during provocative discography and who did not consent to surgical operation.

Results There was a higher correlation between general degeneration and age, as compared with annular disruption and age. Higher general degeneration and annular disruption grades had higher positive rates of discography. However, annular disruption alone was independently associated with positive discography. Age and grade of general degeneration did not affect the prognosis.

Conclusion The grade of general degeneration was associated with age, but it was not correlated with positive discography and prognosis. In addition, high grade of annular disruption correlated with positive discography.
\end{abstract}

Keywords Low back pain, Intervertebral disc degeneration, Radiography, Computed tomography

Received July 7, 2014; Accepted October 6, 2014

Corresponding author: Sang-Heon Lee

Department of Physical Medicine \& Rehabilitation, Korea University Anam Hospital, 73 Inchon-ro, Seongbuk-gu, Seoul 136-705, Korea

Tel: +82-2-920-6471, Fax: +82-2-929-9951, E-mail: spinelee@gmail.com

(c) This is an open-access article distributed under the terms of the Creative Commons Attribution Non-Commercial License (http://creativecommons. org/licenses/by-nc/4.0) which permits unrestricted noncommercial use, distribution, and reproduction in any medium, provided the original work is properly cited.

Copyright $\odot 2015$ by Korean Academy of Rehabilitation Medicine

\section{INTRODUCTION}

Low back pain is a very common symptom and its lifetime prevalence is estimated at $70 \%-85 \%$ [1]. Various pathological structural changes in the lumbosacral region can become the pain source [2,3]. Discogenic back pain is pain originating from a damaged intervertebral disc and its prevalence is estimated at $30 \%$ of patients 
complaining of chronic low back pain without radicular symptoms $[3,4]$.

The diagnosis of discogenic back pain is based on the typical symptoms, physical examination, imaging study and results of discography. Structural abnormalities observed on magnetic resonance imaging (MRI) indicate an increased probability of the disc as the source of low back pain [5,6]. However, the absence of abnormalities on MRI scans does not rule out the disc as the source of pain $[7,8]$. Discography is the only method to directly stimulate and assess the disc as a source of back pain. Discography with appropriate criteria can be useful tool for evaluating discogenic back pain $[9,10]$.

Besides pain provocation, morphological evaluation of discs were performed with fluoroscopy during discography and with computed tomography (CT) after discography [11-13]. Several previous studies indicated that morphologically severe degenerative discs have higher positive rates of discography. Older patients tend to have more severe disc degeneration than younger patients [13]. However, older patients have a lower positive rate of discography despite the presence of more serious degenerative disc changes [14]. Therefore, a degenerated disc does not necessarily result in a painful disc.

Until now, no study has researched the association between disc morphology and prognosis.

The aim of this study was to investigate the correlation among age, disc morphology, positive discography, and prognosis in the patients with chronic low back pain.

\section{MATERIALS AND METHODS}

\section{Subjects}

The study was approved by the Korea University Institutional Review Board in 2014.

We retrospectively collected and analyzed data between May 2011 and April 2014. Total 183 intervertebral discs in 72 patients were studied. All the patients had $>3$ months of axial low back pain with or without referred buttock or thigh pain despite conservative management. Exclusion criteria were previous spine surgery, spinal fracture, tumor, infection, radiculopathy as the main symptom and severe cognitive impairment. All patients received lumbar CT scan after discography. Intradiscal injection of steroid was tried for patients with symptomatic disc identified during provocative discography and who were
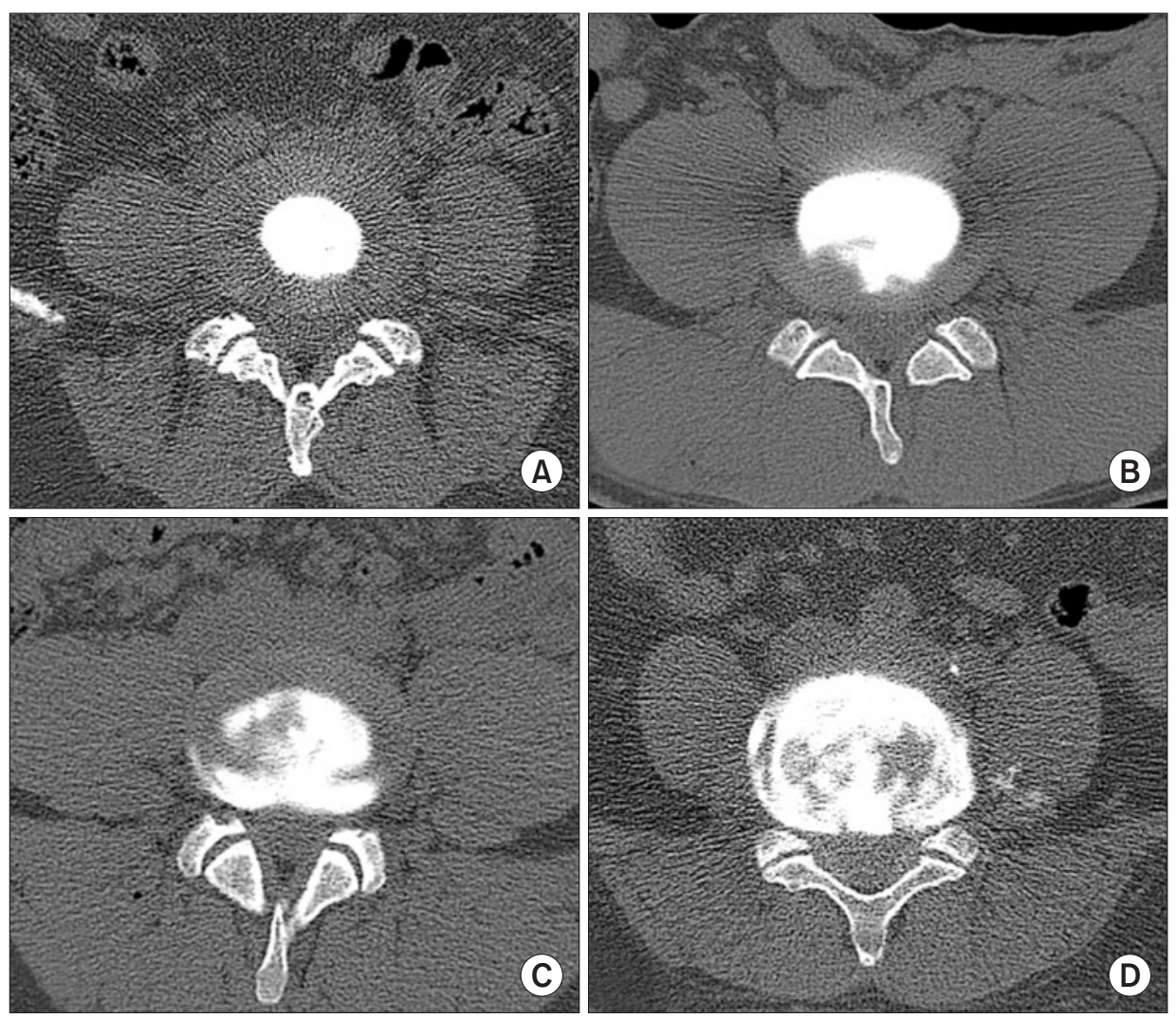

Fig. 1. General degeneration of Dallas discogram description. (A) Grade 0, no change. (B) Grade 1, local $(<10 \%)$. (C) Grade 2, partial (<50\%). (D) Grade 3, total ( $>50 \%)$. 
unwilling to accept surgical operation.

\section{Discography protocol}

We performed pressure controlled discography using a standard posterolateral approach with a 25 -gauge spinal needle. Once the needle was correctly positioned in the center of the disc, the needle was connected to the Automated Pressure-Controlled Discography (APCD) System (Cybermedic, Iksan, Korea) [15]. The contrast medium was injected slowly and pressure of injection was recorded. The patient was required to report if the pain produced was concordant with the accustomed pain together with its intensity. The pain reaction during discography at each level was recorded as follows: no pain, dissimilar pain, similar pain, or concordant pain. Injection was continued until pain was produced, contrast medium escaped from the disc, the volume of injection reached $3 \mathrm{~mL}$, or pressure of injection reached $50 \mathrm{psi}$ [10]. Discs with similar or concordant pain were classified as positive, and discs with no pain or dissimilar pain were classified as negative.

\section{Morphological analysis}

The axial images of post-discography lumbar CT were used to grade the extent of general degeneration and annular disruption according to the Dallas discogram description (DDD) [12]. General degeneration was rated as 0 when normal and progressed to 3 when contrast filled more than half of the annulus (Fig. 1). Annular disruption was graded as 0 when normal and progressed to 3 when contrast escaped beyond outer annulus (Fig. 2). Annular fissure toward the anterior of disc was not considered during rating of annular disruption.

Two independent observers who were blinded to the clinical and discographic findings of patients performed all measurements.

\section{Treatment and outcome measure}

Patients with positive discography were recommended for treatment with intradiscal steroid injection. For the patients who received intradiscal steroid injection, $20 \mathrm{mg}$ of triamcinolone acetonide (total $0.5 \mathrm{~mL}$ ) was injected slowly and gently into the center of the nucleus pulposus of the target intervertebral disc under fluoroscopic guidance.
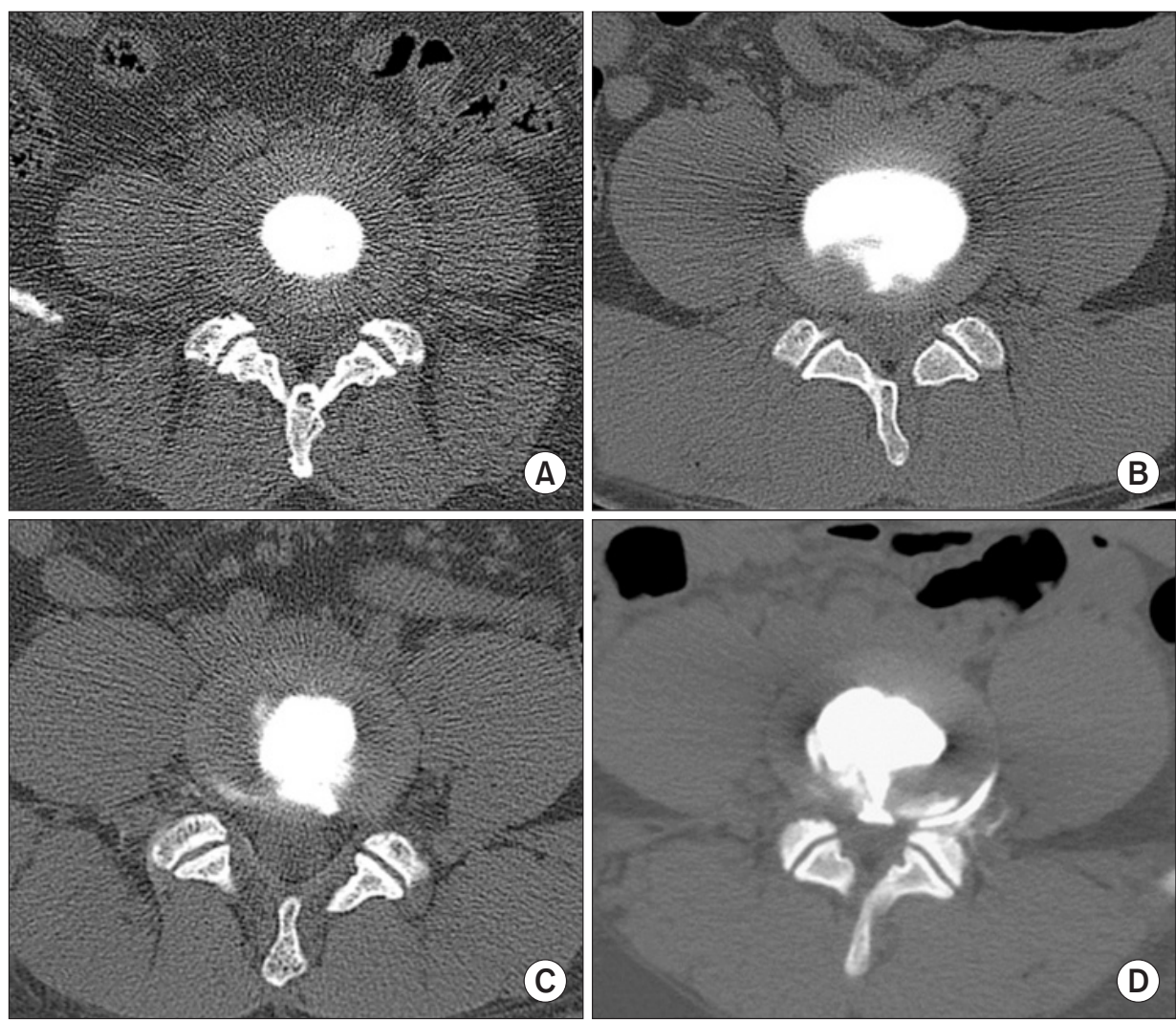

Fig. 2. Annular disruption of Dallas discogram description. (A) Grade 0, none. (B) Grade 1, into inner annulus. (C) Grade 2, into outer annulus. (D) Grade 3, beyond outer annulus. 

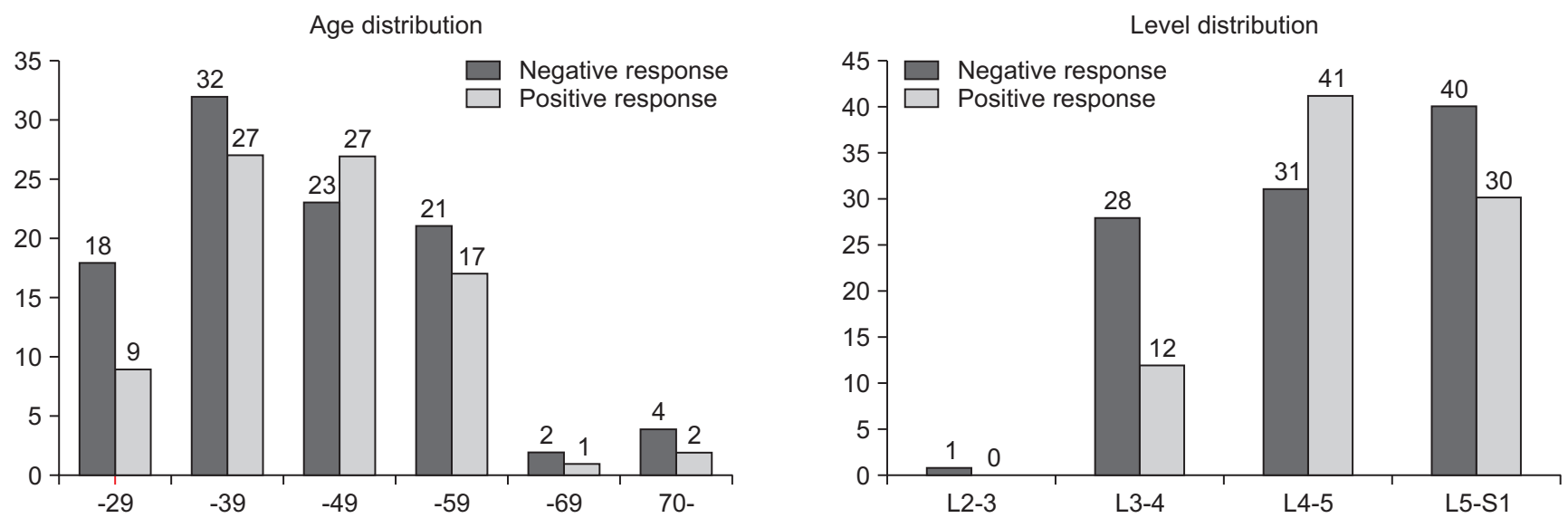

Fig. 3. Distribution of age, examined level and positive discography.

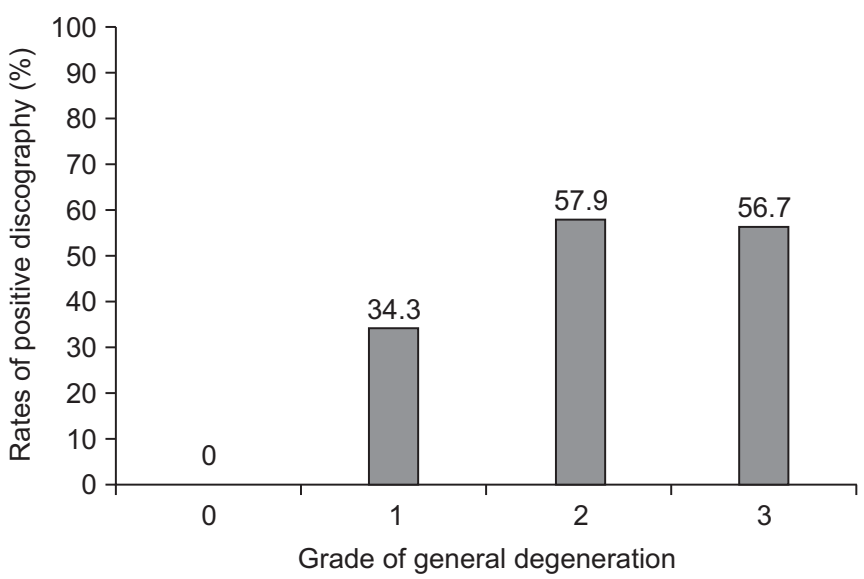

Fig. 4. Grade of general degeneration and rates of positive discography (linear by linear association $=21.530$, $\mathrm{p}<0.001)$. Positive discography is classified discs with similar or concordant pain. Grade 0 , no change; grade 1 , local $(<10 \%)$; grade 2 , partial $(<50 \%)$; grade 3 , total $(>50 \%)$.

Baseline data was obtained before the procedure, and clinical outcome was determined by numerical rating scale (NRS) assessed at 3 months after the procedure.

\section{Statistical analysis}

Categorical data were compared by the chi-square test and linear by linear association. The spearman correlation and binary logistic regression analysis was used to examine the correlation among age, grade of general degeneration, grade of annular disruption and positive discography. Multivariate linear regression analysis was performed to identify association among age, grade of general degeneration and prognosis. Statistical analyses were performed using SPSS Statistics ver. 20 software

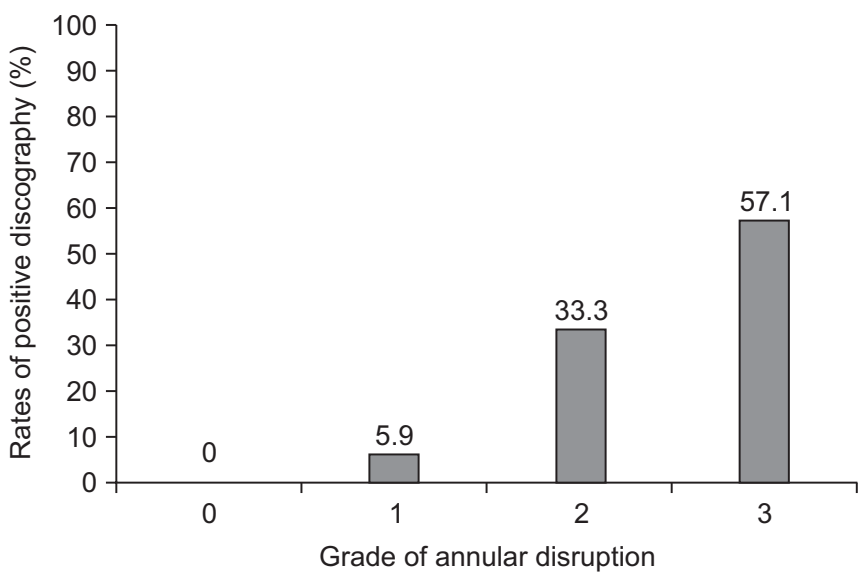

Fig. 5. Grade of annular disruption and rates of positive discography (linear by linear association $=34.425, \mathrm{p}<0.001$ ). Positive discography is classified discs with similar or concordant pain. Grade 0, none; grade 1, into inner annulus; grade 2 , into outer annulus; grade 3 , beyond outer annulus.

(IBM, Armonk, NY, USA). Significance was determined when the $p$-value was $<0.05$.

\section{RESULTS}

\section{Sample characteristics}

Discographies were performed on a total of 183 discs from 72 patients. Distributions of age, examined level and response of discography were shown in Fig. 3.

\section{Correlation between morphology of disc and positive discography}

In the case of general degeneration, the positive rates of grade $0,1,2$, and 3 accounted for $0 \%, 34.3 \%, 57.9 \%$, and 
Table 1. Binary logistic regression model for positive discography according to age and disc morphology

\begin{tabular}{lrrrrrc}
\hline & B & SE & Wald & df & p-value & $\operatorname{Exp(B)}$ \\
\hline Age & -0.015 & 0.015 & 1.035 & 1 & 0.309 & 0.985 \\
Annular disruption & 1.556 & 0.440 & 12.515 & 1 & $<0.001$ & 4.741 \\
General degeneration & 0.076 & 0.255 & 0.089 & 1 & 0.765 & 1.079 \\
Constant & -3.878 & 1.250 & 9.622 & 1 & 0.002 & 0.021 \\
\hline
\end{tabular}

p-value for Hosmer-Lemeshow test is 0.505 .

Table 2. Multivariate linear regression model for improvement on numerical rating scale score according to age and disc morphology

\begin{tabular}{lccccc}
\hline & B & SE & $\beta$ & t & p-value \\
\hline Age & -0.008 & 0.019 & -0.069 & -0.413 & 0.682 \\
General degeneration & 0.401 & 0.344 & 0.194 & 1.167 & 0.250 \\
Constant & 2.000 & 0.947 & - & 2.112 & 0.041 \\
\hline
\end{tabular}

$56.7 \%$, respectively ( $\mathrm{p}$-value for linear by linear association $<0.001$ ) (Fig. 4). In the case of annular disruption, the positive rates of grade $0,1,2$, and 3 constituted $0 \%$, $5.9 \%, 33.3 \%$, and $57.1 \%$, respectively (p-value for linear by linear association $<0.001$ ) (Fig. 5).

\section{Correlation between age and disc morphology}

There was a high correlation between general degeneration and age $(\mathrm{r}=0.376, \mathrm{p}<0.001)$, as compared with annular disruption and age $(\mathrm{r}=0.233, \mathrm{p}=0.002)$.

Correlation among age, disc morphology, and positive discography

By binary logistic regression, annular disruption was independently associated with positive discography $(\operatorname{Exp}(B)=4.741, \mathrm{p}<0.001)($ Table 1$)$.

Correlation among age, disc morphology, and clinical outcome

Data from 43 patients with only 1 symptomatic disc level were analyzed. All the discs of the patients had grade 3 annular disruption. Multivariate linear regression analysis was employed to determine the predictors of improvement on NRS score as dependent variable, and age and grade of degeneration as predictors. According to this model, age ( $\mathrm{p}=0.682)$ and grade of degeneration $(p=0.250)$ were not significant predictors of improvement on NRS score (Table 2).

\section{DISCUSSION}

Intervertebral discs are complex structures that consist of a thick outer fibrous ring, the annulus fibrosus, which surrounds an inner gelatinous center known as the nucleus pulposus, which is further sandwiched between the inferior and superior cartilage end-plates.

The intervertebral disc is subjected to age-related morphological, biochemical changes and degeneration. With advancing age, there is some decrease of proteoglycans and water within the nucleus pulposus, leading to poor hydrodynamic transfer of axial stress to the outer annulus fibrosus. Abnormal distribution of axial stress results in the tearing of the annulus fibrosus, and is followed by reduced structural integrity of the disc [16-18].

Previous autopsy and imaging studies found that discs degenerate much earlier than other musculoskeletal tissues. Miller et al. [19] found that about $20 \%$ of people in the second decade have discs with mild degeneration that increase steeply with age in a study on autopsy specimens. MRI studies reported that disc degeneration was identified in about $20 \%$ of people without low back pain, but in up to $40 \%$ of people complaining of low back pain in the second decade $[20,21]$. Increase in frequency of degeneration was verified on follow-up imaging [21].

Earlier studies with discography combined with CT scanning investigated the relationships among age, disc morphology and the results of the discography. Vanharanta et al. [13] found that painful discs have higher general degeneration and annular disruption scores, 
as compared to painless discs. Our data also showed that higher general degeneration and annular disruption grades had higher positive rates of discography. However, only annular disruption was independently associated with positive discography. Zhang et al. [14] found that older patients with low back pain have a lower positive rate of discography despite the presence of more serious degenerative disc changes. We found a higher correlation between general degeneration and age, as compared with annular disruption and age. As previously stated, because annular disruption was independently associated with positive discography, there was no significant difference in positive rates between age subgroups.

Intradiscal steroid administration for discogenic low back pain has been studied previously, with initial positive results, but the studies were on heterogeneous patient populations and were generally not blinded [22,23]. Two randomized studies investigated the clinical effectiveness of intradiscal steroid injections. Intradiscal steroid injection therapy was supported by 1 study with a 6-month follow-up but not another study with 1-year follow-up $[24,25]$. Although only a palliative therapy, owing to its strengths of minimal invasion and simplicity, intradiscal steroid injection is selected by patients who are unwilling to accept surgery. However, increasing the frequency and dosage of intradiscal steroid injections may further aggravate disc degeneration, promote intervertebral disc calcification, or cause iatrogenic infections $[26,27]$.

Previously, no study examined the correlation between disc morphology and prognosis after intradiscal steroid injection. Our data showed that the grade of general degeneration does not affect prognosis. As a result, the grade of general degeneration has less clinical importance, as compared with annular disruption. Furthermore, grade of annular disruption can provide additional information in equivocal diagnostic situations.

The limitations of this study were as follows. First, the number of patients was small and all subjects had chronic low back pain, hence the study subjects did not represent the general population. Second, because most examined discs were L3/4, L4/5, and L5/S1 level, the results might not be applicable to the L2/3 or higher level discs. Third, there was possible inter-observer and intraobserver disagreement with morphological analysis.

The results of this study demonstrated that the grade of general degeneration was associated with age, but it was not correlated with positive discography and prognosis. High grade of annular disruption correlated well with positive discography.

\section{CONFLICT OF INTEREST}

No potential conflict of interest relevant to this article was reported.

\section{REFERENCES}

1. Andersson GB. Epidemiological features of chronic low-back pain. Lancet 1999;354:581-5.

2. Kuslich SD, Ulstrom CL, Michael CJ. The tissue origin of low back pain and sciatica: a report of pain response to tissue stimulation during operations on the lumbar spine using local anesthesia. Orthop Clin North Am 1991;22:181-7.

3. Manchikanti L, Singh V, Pampati V, Damron KS, Barnhill RC, Beyer C, et al. Evaluation of the relative contributions of various structures in chronic low back pain. Pain Physician 2001;4:308-16.

4. Schwarzer AC, Aprill CN, Derby R, Fortin J, Kine G, Bogduk N. The relative contributions of the disc and zygapophyseal joint in chronic low back pain. Spine (Phila Pa 1976) 1994;19:801-6.

5. Hancock MJ, Maher CG, Latimer J, Spindler MF, McAuley JH, Laslett M, et al. Systematic review of tests to identify the disc, SIJ or facet joint as the source of low back pain. Eur Spine J 2007;16:1539-50.

6. Kang CH, Kim YH, Lee SH, Derby R, Kim JH, Chung $\mathrm{KB}$, et al. Can magnetic resonance imaging accurately predict concordant pain provocation during provocative disc injection? Skeletal Radiol 2009;38:877-85.

7. Horton WC, Daftari TK. Which disc as visualized by magnetic resonance imaging is actually a source of pain? A correlation between magnetic resonance imaging and discography. Spine (Phila Pa 1976) 1992;17(6 Suppl):S164-71.

8. Zucherman J, Derby R, Hsu K, Picetti G, Kaiser J, Schofferman J, et al. Normal magnetic resonance imaging with abnormal discography. Spine (Phila Pa 1976) 1988;13:1355-9.

9. Manchikanti L, Glaser SE, Wolfer L, Derby R, Cohen SP. Systematic review of lumbar discography as a di- 
agnostic test for chronic low back pain. Pain Physician 2009;12:541-59.

10. Wolfer LR, Derby R, Lee JE, Lee SH. Systematic review of lumbar provocation discography in asymptomatic subjects with a meta-analysis of false-positive rates. Pain Physician 2008;11:513-38.

11. Adams MA, Dolan P, Hutton WC. The stages of disc degeneration as revealed by discograms. J Bone Joint Surg Br 1986;68:36-41.

12. Sachs BL, Vanharanta H, Spivey MA, Guyer RD, Videman T, Rashbaum RF, et al. Dallas discogram description: a new classification of CT/discography in lowback disorders. Spine (Phila Pa 1976) 1987;12:287-94.

13. Vanharanta H, Sachs BL, Spivey MA, Guyer RD, Hochschuler SH, Rashbaum RF, et al. The relationship of pain provocation to lumbar disc deterioration as seen by CT/discography. Spine (Phila Pa 1976) 1987;12:295-8.

14.Zhang JD, Xia Q, Hu YC, Miao J, Feng QJ. Analysis of the relationship between morphology of intervertebral disc and some correlated factors following discography in patients with chronic low back pain. Orthop Surg 2009;1:47-51.

15. Derby R, Lee SH, Lee JE, Lee SH. Comparison of pressure-controlled provocation discography using automated versus manual syringe pump manometry in patients with chronic low back pain. Pain Med 2011;12:18-26.

16. Urban JP, Roberts S. Degeneration of the intervertebral disc. Arthritis Res Ther 2003;5:120-30.

17. Adams MA, Roughley PJ. What is intervertebral disc degeneration, and what causes it? Spine (Phila Pa 1976) 2006;31:2151-61.

18. Haefeli M, Kalberer F, Saegesser D, Nerlich AG, Boos N, Paesold G. The course of macroscopic degeneration in the human lumbar intervertebral disc. Spine (Phila Pa 1976) 2006;31:1522-31.
19. Miller JA, Schmatz C, Schultz AB. Lumbar disc degeneration: correlation with age, sex, and spine level in 600 autopsy specimens. Spine (Phila Pa 1976) 1988;13:173-8.

20. Tertti MO, Salminen JJ, Paajanen HE, Terho PH, Kormano MJ. Low-back pain and disk degeneration in children: a case-control MR imaging study. Radiology 1991;180:503-7.

21. Erkintalo MO, Salminen JJ, Alanen AM, Paajanen HE, Kormano MJ. Development of degenerative changes in the lumbar intervertebral disk: results of a prospective MR imaging study in adolescents with and without low-back pain. Radiology 1995;196:529-33.

22. Feffer HL. Treatment of low-back and sciatic pain by the injection of hydrocortisone into degenerated intervertebral discs. J Bone Joint Surg Am 1956;38A:585-92.

23. Feffer HL. Therapeutic intradiscal hydrocortisone: a long-term study. Clin Orthop Relat Res 1969;67:100-4.

24. Khot A, Bowditch M, Powell J, Sharp D. The use of intradiscal steroid therapy for lumbar spinal discogenic pain: a randomized controlled trial. Spine (Phila $\mathrm{Pa}$ 1976) 2004;29:833-7.

25. Cao P, Jiang L, Zhuang C, Yang Y, Zhang Z, Chen W, et al. Intradiscal injection therapy for degenerative chronic discogenic low back pain with end plate Modic changes. Spine J 2011;11:100-6.

26. Aoki M, Kato F, Mimatsu K, Iwata H. Histologic changes in the intervertebral disc after intradiscal injections of methylprednisolone acetate in rabbits. Spine (Phila Pa 1976) 1997;22:127-32.

27. Carragee EJ, Don AS, Hurwitz EL, Cuellar JM, Carrino JA, Herzog R. 2009 ISSLS Prize Winner: does discography cause accelerated progression of degeneration changes in the lumbar disc: a ten-year matched cohort study. Spine (Phila Pa 1976) 2009;34:2338-45. 